Clemson University

TigerPrints

8-2020

\title{
Pueblo Pequeño, Infierno Grande: Shifting the burden of Latinx Spanish teacher retention in the rural South
}

\author{
Cornelia V. Okraski \\ University of North Carolina at Chapel Hill \\ Stephanie M. Madison \\ Clemson University, stephm@clemson.edu
}

Follow this and additional works at: https://tigerprints.clemson.edu/ed_human_dvlpmnt_pub

Part of the Educational Assessment, Evaluation, and Research Commons

\section{Recommended Citation}

Okraski, CV, Madison, SM. Pueblo Pequeño, Infierno Grande: Shifting the burden of Latinx Spanish teacher retention in the rural South. Foreign Language Annals. 2020; 1- 19. https://doi.org/10.1111/flan.12474

This Article is brought to you for free and open access by the Education \& Human Development at TigerPrints. It has been accepted for inclusion in Publications by an authorized administrator of TigerPrints. For more information, please contact kokeefe@clemson.edu. 


\title{
Pueblo Pequeño, Infierno Grande: Shifting the burden of Latinx Spanish teacher retention in the rural South
}

\author{
Cornelia V. Okraski ${ }^{1} \quad$ Stephanie M. Madison PhD $^{2}$ (D)
}

\section{The Challenge}

Recruiting and retaining World Language teachers in the rural South is difficult. It is even more challenging for Latinx teachers of the Spanish language. How do Latinx Spanish teachers in the rural South perceive experiences that help or hinder retention? In what ways are Latinx Spanish teachers navigating their role as advocates for linguistic and cultural diversity in their rural schools and communities?

${ }^{1}$ Department of Middle, Secondary, and K-12 Education, College of Education, University of North Carolina at Charlotte, Charlotte, North Carolina

${ }^{2}$ Clemson University, Clemson,

South Carolina

\section{Correspondence}

Cornelia V. Okraski, Department of Middle, Secondary, and K-12 Education, College of Education, 9201 University City Boulevard, Charlotte, NC 28223.

Email: cokraski@uncc.edu

\section{Funding information}

American Council on The Teaching of Foreign Languages

\section{Abstract}

This study explored the experiences of five Latinx Spanish teachers who worked in schools in rural North Carolina and South Carolina. Using data from 25 semistructured interviews and publicly available school/community demographic information, this qualitative multiple-case study sought to answer the following questions: (a) How do Latinx Spanish teachers in the rural South perceive experiences that help or hinder retention? (b) In what ways are Latinx Spanish teachers navigating their role as advocates for linguistic and cultural diversity in their rural schools and communities? Findings showed that participants were constantly balancing the benefits and challenges of their work in a rural area. Due to the racialized nature of the Spanish language, participants reported instances of Spanish being conflated with immigration which resulted in hostility from 
both students and adults. Nonetheless, participants felt a sense of responsibility in providing their students with exposure to cultures outside of their own cultural setting. As working conditions can have a profound effect on a teacher's decision to stay in the classroom, the findings suggest that emphasizing the positive aspects of teaching in a challenging context may encourage teacher retention.

\section{KEYWORDS}

Latinx teachers, rural schools, teacher retention

\section{1 | INTRODUCTION}

The teacher shortage in World Languages (WL) has been a critical issue for decades (Boe \& Gilford, 1992; Swanson, 2008; Swanson \& Mason, 2018). A national report published by the U.S. Department of Education in 2017 showed that WL teaching positions were the most difficult to fill, more so than other teacher-shortage areas such as special education, math, and science (American Academy of Arts and Sciences, 2017). Moreover, the U.S. Department of Education (2017) reported WL teacher shortages for 44 states.

Further compounding the problem is the challenge of recruiting and retaining teachers in rural areas. School districts in rural areas have difficulty attracting teachers because of the perceptions of low salaries, social isolation, and geographic isolation (Monk, 2007; National Association of State Boards of Education, 2016; Schwartzbeck, Redfield, Morris \& Hammer, 2003). The Center for Public Education (Lavalley, 2018) described how rural school districts employ a critically high percentage of new teachers (defined as $17 \%$ or more of the teaching staff), leading to high turnover rates. Rural schools experience more difficulties recruiting faculty and filling vacancies than nonrural schools (Aragon, 2016; Player, 2015). In addition, teachers in the South are more likely to leave than those in other regions, making retention an issue of primary concern; indeed, "the lion's share of the demand for teachers is caused by attrition” (Sutcher, Darling-Hammond, \& Carver-Thomas, 2016, p. 4). Despite attempts to highlight the positive aspects of working in the rural South, (i.e., National Association of State Boards of Education, 2016), the teacher-shortage challenges are real and ongoing.

Much of the narrative of teacher retention centers on teachers quitting or leaving because they gave up or chose to abandon the profession. However, there are many factors that influence a teacher's decision to leave as well as their decision to stay. These working conditions include class sizes, teaching load, administrative and collegial support, and availability of materials, in addition to teacher inclusion in decision-making and opportunities for professional development (Darling-Hammond \& Ducommun, 2007; Darling-Hammond, 2003). Moreover, in rural areas, it is critical for the beliefs and values of the community to be reflected in the school in order to help foster a positive working environment for teachers, as community support can be an invaluable resource (Lowe, 2006). However, Acheson, Taylor, and Luna (2016) found that rural WL teachers perceived a distinct lack of community and institutional support when students and parents expressed negative attitudes about Spanish language 
learning as it was tied to hostile beliefs about immigration. The complex relationship between teachers, communities, and working conditions can help or hinder teacher retention with the rural South being no exception.

For the purpose of this study, the researchers determined rural communities by considering population density of 250 people per square mile or less and geographic distance of at least 10 miles from urbanized areas (Bunch, 2008; Lavalley, 2018; North Carolina Rural Center, n.d.; United States Census Bureau, 2017). Though rural areas are often considered homogenous, in truth, they defy generalities and contain a spectrum of diverse populations (Monk, 2007; National Association of State Boards of Education, 2016). Flora, Flora, and Gasteyer (2016) examined the diversity of rural America, recognizing that government labels for rural places may differ from those established by scholars for the purpose of analysis.

In light of the WL teacher shortage, this qualitative multiple-case study explored the experiences of five Latinx Spanish teachers in rural North Carolina and South Carolina ("the Carolinas") in order to better understand not only difficulties but also fulfilling aspects of their job that encourage retention. By focusing on these teachers' perceptions of racism, the benefits and challenges of teaching in a rural community, and their role as a cultural broker, we hope to shed light on not only the difficulties that might influence decisions to leave the profession but also the positives that help teachers make the decision to stay. The term "Latinx" is used throughout this paper as a more gender-inclusive alternative to Latino or Latina (Salinas \& Lozano, 2019).

\section{2 | LITERATURE REVIEW}

Retaining WL teachers in the rural South is a paramount concern. As such, a deeper understanding of teachers' perceptions and experiences can help broaden systems of support where they are most needed. This review of the literature first explains the shifting demographics of certain rural areas while acknowledging that others remain divided along racial lines. Next, research on WL teachers in rural areas is outlined to demonstrate the pattern of challenges and benefits unique to their teaching context. The literature review then describes how serving as a cultural broker can be a fulfilling and engaging role for WL teachers. These considerations helped shape this study's research questions specific to the Carolinas.

\section{1 | Demographics in the Carolinas}

In the rural American South, different realities exist in different areas. Some places, both rural and suburban, are experiencing rapid population growth as newly emerging immigrant communities where educators and administrators are often overwhelmed by the dramatically changing ethnic and socioeconomic background of their students (Wainer, 2004). North Carolina, for example, experienced a more than $300 \%$ increase in the Latinx K-12 student population between 2000 and 2014 (Tippett, 2014). Between 2000 and 2016, South Carolina saw a more than $700 \%$ increase in all English Language Learner students, with the majority speakers of Spanish (National Center for Education Statistics, 2018). This demographic phenomenon, known as the "New Latino Diaspora" or the "New Latino South," is the focus of a small yet important body of literature (e.g., Hamann \& Harklau, 2010; Hamann, Wortham, \& Murillo, 2002; Marrow, 2011; Salas \& Portes, 2017).

On the contrary, many areas in the Carolinas remain deeply isolated and largely segregated with the population reflecting primarily Black or White students (Bowers, Smith, Adcox, 
Hawes, \& Moore, 2018; Hawes \& Parker, 2015). For example, a study of 2,169 public high schools in Georgia, Kentucky, Louisiana, North Carolina, South Carolina, Tennessee, and Mississippi labeled 323 schools as predominantly Black (>75\% enrollment) and 765 schools as predominantly White ( $>75 \%$ enrollment; Bryant, 2019). The study determined that schools in the South are "deeply segregated" with over half of the schools in the sample considered "highly segregated," resulting in disparate academic outcomes (p. 9). In these types of schools in the rural South, Latinx Spanish teachers may find few students who look like them.

\section{2 | Teaching WL in rural contexts}

Challenges experienced by WL teachers in rural communities may be related to the mismatch between teachers and students in terms of racial, linguistic, and sociocultural differences. WL teachers who are unfamiliar with a rural school and its rural community may experience tensions when encountering perspectives of students, parents, and school administrators who are unfamiliar with and unwilling to accept worldviews based on linguistic and cultural diversity. As a result, teaching WL and world cultures may seem a daunting or impossible task. Swanson and Huff (2010) measured the perceived level of efficacy (in teaching WL) among rural WL teachers in Georgia in their efforts to identify and examine WL teachers who were planning to leave the profession. The study found that "teachers in rural districts may need specific guidance and strategies to motivate students to learn a second language while living in a more homogeneous cultural setting" (p. 25). Continuing this line of research, a study by Acheson et al. (2016) explored the emotion work of five WL teachers in one high school in rural Georgia. The researchers looked at the emotional burnout of teachers who perceived a lack of community and institutional support for WL teachers and felt an excessive burden for motivation of students. Echoing these findings, a study by Fogle and Moser (2017) examined the personal and professional trajectories of WL and English as a Second Language (ESL) teachers in rural schools in Mississippi. The researchers found that both WL and ESL teachers positioned themselves against dominant ideologies and educational policies and constructed themselves as agents of change in the classroom, school, and the community at large. In the rural South, these teachers served as more than content-knowledge experts, but also served as motivators for students, as advocates for diversity and tolerance, and as a bridge to world cultures outside of students' rural communities.

\subsection{Cultural brokers in rural areas}

Historically, the term cultural broker has referred to someone who navigates and communicates between two different cultures, languages, and social systems. In schools, cultural brokers may be adults who help ease the burden of Latinx youth (Cooper, Denner, \& Lopez, 1999). On the contrary, cultural brokers may be the bilingual children of Spanish-speaking parents who serve as liaisons between the home and the outside world (Orellana, 2009). A cultural broker may also be a teacher or instructional coach who is working to bridge the gap between home and school cultures, particularly for Latinx students (Colomer, 2014; Nieto, 2017; Souto-Manning, 2006; Wyatt, Chapman de Sousa, \& Mendenhall, 2017). For the purpose of this study, we will also use the term cultural broker as a way to describe how Latinx Spanish teachers serve as a bridge to cultures to which their rural students seldom have access. Instead 
of linking Latinx students to the dominant culture of the school, it is linking rural students from the dominant culture to new ways of thinking about the world.

\subsection{Latinx teachers in the Carolinas}

Little has been written about Latinx Spanish teachers in the rural South, but even less has been written specifically about the Carolinas. In response to this lack of research, our questions focus specifically on this region, and North Carolina and South Carolina in particular, as a part of the New Latino South juxtaposed against historically segregated schools that persist to this day. This study sought to answer the following research questions: (a) How do Latinx Spanish teachers in the rural South perceive experiences that help or hinder retention? (b) In what ways are Latinx Spanish teachers navigating their role as advocates for linguistic and cultural diversity in their rural schools and communities?

\section{3 | METHODS}

\section{1 | Qualitative design}

The study is a qualitative multiple-case study, in which the cases were limited to Latinx teachers of Spanish in a rural middle or high school in North Carolina and South Carolina (Merriam, 1998). Data were collected from 25 interviews; five per participant. Participants included two men and three women who were interviewed in English during a 5-month period. Some participants used occasional short strings of Spanish words which were always further explained in English. These statements were translated by the researchers. Drawing on prior studies, researchers developed an interview protocol. The open-ended questions in semistructured interviews (see Appendix A), as part of a larger study, addressed their experiences working in a rural area as a Latinx person and native speaker of Spanish. Additional data were demographic in nature and were drawn from school district websites and census data related to the participants' schools and rural communities.

\section{2 | Participant selection}

Purposeful sampling was used to select participants (Creswell \& Plano Clark, 2018). The researchers sought to include the perspectives of WL teachers of both genders, although gender was not a criterion for the study and generalizations regarding teacher identity on the basis of gender were not the focus of the current study. Participants were recruited through professional teacher organizations, at teacher conferences, and through referrals from other WL teachers who are known to the researchers. All participants were given pseudonyms. Participants were from different countries/territories, but for the purposes of this study were grouped together as Latinx because of the "racialized nature of Latino/Hispanic identity" (Hamann \& Harklau, 2010, p. 158).

Originally from Colombia, David was recruited through the Visiting International Faculty (VIF) program, also known as the International Visiting Teachers Program (South Carolina Department of Education, 2019). He lost his teaching job during layoffs as part of the 2008 
financial crisis. David ultimately moved from a large, urban area to a small, rural area in the Carolinas. The second male participant, Eduardo, moved to the U.S. mainland from Puerto Rico as a teenager and was educated at a university in the American Midwest. Eduardo moved to the Carolinas to teach high school and to be near family. Also from Puerto Rico, Guadalupe moved to the Carolinas as a teenager. She was educated at a nearby university but did not initially prepare for a teaching career. She turned to teaching Spanish when asked by a local school, added relevant coursework while teaching, and has taught Spanish for more than 30 years. Like David, Luisa was recruited as a VIF teacher. Luisa is originally from Costa Rica and was hired as a permanent employee to teach Spanish for Native Speakers in a rural school in the Carolinas. Finally, Natalia was also recruited as a VIF teacher. Natalia is from Colombia and is currently teaching middle school Spanish and a college-readiness course.

All five participants were raised in Spanish-speaking households. Four of the participants had lived in the American South (North Carolina and South Carolina) for at least 9 years; Eduardo was in his fourth year of teaching, all of which took place in the rural South. Eduardo and Guadalupe had moved from Puerto Rico as teenagers whereas the remaining three teachers had been recruited by the VIF program to work as Spanish or ESL teachers in schools in the rural South. These three participants (David, Luisa, and Natalia) received teacher training and worked as English teachers in their respective home countries prior to being recruited by VIF. At the time of the study, all participants taught Spanish as a WL, a course for college-bound students; however, a WL is not a high school graduation requirement in North Carolina or South Carolina. One participant (Luisa) taught Spanish for Native Speakers courses in addition to teaching Spanish as a WL.

\section{3 | Setting}

Each teacher worked in a middle or high school in a distant or remote rural community situated at least 10 miles from an urbanized area. These communities are located in North Carolina and South Carolina in various geographic points in each state. Four of the communities had fewer than 5,700 residents, whereas one community was home to 15,500 residents due to an administrative combination of smaller townships (Table 1). All five schools had fewer than 900 students, with the smallest school housing 380 students. The median household income for the communities in this study ranged from almost $\$ 22,000$ to just over $\$ 32,000$, in sharp contrast to the median household income of approximately $\$ 50,000$ in each of the two states (United States Census Bureau, 2017). In each of the schools in this study, at least $50 \%$ of the student population was identified as Economically Disadvantaged Students (EDS) and qualified for free or reduced lunch. Student demographics at the five schools varied, with two schools (schools \#3 and \#5) where White students were the dominant group. In the remaining three schools, the percentage of Black students ranged from $50 \%$ to $57 \%$. In two schools, only $1 \%$ of students were Hispanic; however, in the remaining three schools, Hispanic students made up 5\%, $12 \%$, and $25 \%$ of the student population, respectively.

\section{4 | Positionality}

As former WL language teachers, both researchers previously taught in rural schools in the Carolinas. As bilingual/multilingual White females, they met and befriended Latinx WL teacher 
TABLE 1 Community and school data

\begin{tabular}{ll}
\hline Site & Demographics \\
\hline School \#1 & $\begin{array}{l}\text { Community: 5,700 residents; median household income } \$ 21,897 \\
\text { School: } 700 \text { students; } 70 \% \text { EDS } ; 50 \% \text { Black, } 46 \% \text { White, } 1 \% \text { Hispanic }\end{array}$ \\
\hline School \#2 & $\begin{array}{l}\text { Community: 5,600 residents; median household income } \$ 27,518 \\
\text { School: } 900 \text { students; } 75 \% \text { EDS; } 57 \% \text { Black, } 41 \% \text { White, } 1 \% \text { Hispanic }\end{array}$ \\
\hline School \#3 & $\begin{array}{l}\text { Community: } 15,500^{\mathrm{b}} \text { residents; median household income } \$ 35,500 \\
\text { School: } 875 \text { students; } 50 \% \text { EDS; } 25 \% \text { Black, } 65 \% \text { White, } 5 \% \text { Hispanic }\end{array}$ \\
\hline School \#4 & $\begin{array}{l}\text { Community: } 1,600 \text { residents; median household income } \$ 29,600 \\
\text { School: } 800 \text { students; } 90 \% \text { EDS; } 53 \% \text { Black, } 20 \% \text { White, } 25 \% \text { Hispanic }\end{array}$ \\
\hline Community: 5,100 residents; median household income $\$ 32,100$ \\
\hline 5
\end{tabular}

${ }^{a}$ Economically disadvantaged students (EDS), which takes into account household income, free/reduced lunch status, and other indicators.

${ }^{\mathrm{b}}$ Combined with several neighboring townships.

colleagues in communities of the rural South through their leadership roles in state language organizations. Both researchers speak with native and native-like American English accents, which may not make their membership in multilingual communities obvious. They emphasized shared experiences as former K-12 WL teachers with participants before asking them to share their own challenges in their professional lives that were related to their racial, linguistic, and cultural differences with the mainstream population in their rural schools. However, because the researchers do not share the Latinx heritage of participants, they conducted member checks upon the completion of the study to ensure they portrayed these stories as accurately as possible. Ultimately, participants may have chosen not to share all of their lived experiences with the researchers as privileged outsiders who were given the opportunity to be guests in their culture. A possible language barrier or miscommunication could have interfered with the understanding of particular statements, even if the researchers asked for clarification. Statements in Spanish were transcribed in Spanish by the researchers themselves.

\section{5 | Data collection}

Data were collected from multiple sources including a series of interviews with Latinx Spanish teachers in rural communities of the Carolinas and publicly available school district demographic and census data related to the participants' schools and rural communities. Over a 5-month period, the researchers conducted almost 8 hours of semistructured interviews with the five participants for an average of 19 minutes per interview. The researchers planned multiple short interviews to best fit the participants' planning periods. As a result, one topic per interview was addressed. Topics included personal and professional background, school's view of WLs, students' funds of knowledge, language and literacy, and cultural and linguistic diversity. The researchers met periodically to discuss interview responses and shape future interviews. When commonalities were identified across participants' responses, the researchers then posed similar questions to subsequent participants. All interviews were audio-recorded 
and transcribed by the researchers. After an initial analysis of the interview data, the researchers met and discussed the implications of the analysis and subsequently adjusted questions for follow-up interviews.

\section{6 | Data analysis}

Following Merriam (1998), the researchers viewed data analysis as "the process of making sense out of the data... [which] involves consolidating, reducing, and interpreting what people have said and what the researcher has seen and read-it is the process of making meaning" (p. 178). Researchers first completed a round of open coding, discussed individual conclusions, and determined broad themes across all participants in order to answer the two research questions. Care was taken to focus specifically on responses that aligned with possible reasons for the teachers' retention, as well as areas in which they might be better supported. Then, researchers completed a round of axial coding to develop more specific subthemes and apply these themes across all participants. Three patterns emerged, and specific quotes were matched with these patterns. Patterns included experiences with racism, the double-edged sword of teaching Spanish in a rural setting, and cultural brokers in distinct contexts. Finally, researchers compared the demographic data of participants, their specific teaching and community contexts, the established codes and themes, and their quotes that matched these specific themes. These data told the story of each participant, and researchers selected illustrative examples in the findings. The data were compared with the experiences of all other participants in order to form conclusions about the common lived experiences of these teachers.

Member checking was used at the conclusion of the study. Researchers shared manuscript drafts and received feedback to ensure the interpretations were accurate and truly reflective of the lived experiences of participants. In order to decrease threats to validity, researchers utilized member checks to "gain the needed confirmation, to increase credence in the interpretation, to demonstrate commonality of an assertion” (Stake, 1995, p. 112).

\section{4 | FINDINGS}

The findings revealed many shared experiences across all five participants. For the specific research questions in the study, three main findings emerged. Tying many of these themes together can be summed up in a quote by David when describing how working in a small, rural community influenced how students saw themselves and each other. He said, "In Spanish, we have a saying, it says, 'Pueblo pequeño, infierno grande." That is to say, in a small town in which there isn't much to do and there isn't much exposure to outside points of view, isolated community life can be hell.

\section{1 | Finding \#1: Experiences with racism}

The racialized nature of Spanish and, by extension, speakers of the Spanish language, can lead to experiences with racism outside of the typical Black and White divide, so commonly found in schools in the Carolinas. Participants reported racism in ways both subtle and obvious in their rural schools. 


\subsection{1 | Hostility towards Spanish}

Participants reported resistance to using and teaching the Spanish language in their schools. This resistance came from colleagues, parents, and students in different forms. In addition, the attitudes and behaviors observed by the participants led to the perception that their Spanish language class was not highly valued in their community.

One example of hostility towards Spanish from colleagues occurred when David was describing a faculty meeting after school in which he was chatting in Spanish with another teacher. He said, "We were talking and then the librarian said, 'English please.' I said, 'Wow, really.' She wasn't included in the conversation [...] but she said, 'English please.' It was not the first time it happened." Natalia reported a similar attitude from parents. She felt they were not supportive of her Spanish class and she said it was hard for her "knowing that, you know, not to have the support at home because actually they, they [parents] wish the program was not even at school." Both Natalia and David worked at schools with a low percentage of Hispanic students, suggesting that those in the community may have lacked personal contact with Latinx people, thus reinforcing stereotypes.

This negative attitude was also reflected in the students. Eduardo's school hired several international teachers to staff positions that had gone unfilled. The students, however, were not always kind or respectful to these teachers. He explained, "The students are very proactive about... making sure that the teachers feel unwelcomed. By either saying things about them or saying things to them, about the way that they speak or the way that they act." Though all participants were clear that this behavior was not constant or expressed by every person they encountered, it was common enough to make a deep impact on their perception of belonging as a Spanish speaker.

\subsection{2 | Hostility towards immigrants}

Due to the racialized nature of the Spanish language, participants reported instances of Spanish being conflated with immigration. In the rural South, as in other parts of the United States, immigration is an incendiary topic that can elicit a strong emotional response, by both those in favor and opposed. Indeed, participants in the current study reported hostile beliefs about immigration from community members and from their students.

At Eduardo's school, Hispanic students made up only $1 \%$ of the student population. He struggled with the hostility towards immigrants when he first started teaching at the school and recognized that his Spanish class represented much more than merely a place to learn a language. He recounted:

In the beginning, I felt like it was a personal attack to me. But then, as I got to know the community itself, I understood that it's just a mentality of that, as being around for generation after generation. Spanish, languages in general, things along those lines... I just feel like just because of the common connotation, oh, Spanish means immigration and we don't want immigration. That type of mentality of people believing that immigration to the U.S. is bad, and they associate Spanish 100\% with immigration to the U.S. 
Eduardo's experience was not unique. The immigration link to Spanish came up time and again throughout the interviews. Luisa, however, took an approach of resistance and challenged people, both colleagues and students, when she heard statements disparaging immigrants. For example, when she overheard people say undocumented Latinx immigrants don't pay taxes, she said, "Latino families still have to go to the grocery store and put gas in their cars, you know. They're paying taxes when they're doing all these things." Small but consistent acts of resistance were mentioned throughout the interviews, indicating an uneasy sense of wellbeing within these particular communities.

\section{2 | Findings \#2: The double-edged sword of teaching Spanish in a rural setting}

For participants in this study, the rural setting deeply impacted their professional lives. The rural South, notorious for poverty and racial inequity, can also be a place where opportunities arise. When examining teacher experiences, it is important to note the ways in which the context both helps and hinders the factors that influence teacher retention and attrition.

\subsection{1 | Benefits of teaching Spanish in a rural setting}

Though the challenging aspects of working in a rural school are well-documented and are a source of great concern for teacher retention, the positive aspects are seldom given much attention. Yet, despite the challenges associated with their teaching context, participants acknowledged that working in a rural school also provided professional opportunities that a larger school might not afford.

Professional development can occur through attendance at conferences to not only learn new teaching strategies but to further build a community with like-minded colleagues. Rural schools are notorious for lacking funds due to deeply entrenched poverty, and for this reason, professional development for teachers may not always be possible. However, Guadalupe reported a different experience. Even though her school has a high EDS percentage, she reported attendance at the state WL teacher conference for 27 of the past 30 years of teaching. Her colleagues and administration were supportive of her professional development, perhaps contributing to her decision to remain in the classroom in a rural school for so long.

Eduardo also reported a positive experience with inclusion in decision-making. He received his teacher training in the United States and mentioned many of his classmates struggled to find a job in urban areas in northern states, whereas he was hired immediately in the rural Carolinas. Though he recognized the difference in pay, prestige, and access to materials between his school and those of his classmates in large cities, he also recognized the opportunities that his position offered. For example, when he spoke about his participation in a school-wide literacy initiative, he said:

There's a lot of opportunities within rural communities to be able to actually excel at the things you didn't even know you were capable of excelling at. As a teacher, I've found that coming here, I only have a bachelor's degree and I'm only certified to be a Spanish teacher, but I'm in charge of a lot of different things, just because nobody is doing it. You can just do it. 
These experiences were not unique to Guadalupe and Eduardo. Rather, all participants mentioned how much they appreciated professional development and being included in school initiatives. To be fair, none of the participants reported access to funding for attending national conferences or large-scale events. Yet participation in local and regional events was sufficient to provide the professional community needed to help balance the challenging aspects of the job.

\subsection{2 | Challenges of teaching Spanish in a rural setting}

The school populations in this study reflected primarily Black and White students with a much smaller percentage of Latinx students and few if any, students outside of these demographics. Participants perceived that a lack of exposure to other ways of thinking created a limited worldview on the part of students and parents. As a result, participants often struggled with feeling accepted as a professional and feeling validated as a Latinx individual in the community, even though they experienced acceptance and validation in their professional lives in other ways.

David worked in one of the schools from this study with the least amount of diversity outside of Black and White students. He reported his students seldom interacted outside of racial divides, an observation actually noted by all participants. This divide impacted working conditions, as race became unavoidable and prominent in nearly all interactions. As a teacher who was educated outside of the United States, David was surprised to see this behavior in his students. He said, "I thought that Americans were going to be more open to diversity. This is a very unique country that is surrounded by people from many nationalities, different languages, cultures. But. They [students] don't see different, they just see weird." What David failed to realize was the rural South was not as diverse as he initially believed.

Natalia echoed this observation of a sharp focus on race in the school. She believed her race was not only problematic with being accepted by the community, but she also believed it impacted student motivation in her class. When reflecting on her first years at the school, she said:

It was not like that harmony at the beginning, it was a struggle. [...] I don't have the part that they can relate to me because of my, for example, for my race, so that part that I needed to kind of gain their, maybe their trust, or believing in the program or believing why Spanish is important to learn even if they're not planning to leave the U.S. or just to see it as an opportunity they have at school.

Natalia and David's experiences illustrated the difficult task of motivating students who perceive cultural differences as "weird" or unrelatable. These working conditions can be exhausting for teachers, and as we know, working conditions are incredibly influential for teacher retention. Though participants were happy, overall, with how their schools allowed them to take on leadership positions, have an active role in decision-making, and attend professional development at the local level, the question becomes whether these benefits are enough to outweigh the challenges.

\section{3 | Finding \#3: Cultural brokers in distinct contexts}

While struggling with the benefits and challenges of working in a rural setting, participants also reported feeling a sense of responsibility for exposing students to other worldviews and ways of 
life that they would otherwise probably not encounter. These teachers viewed their job as much more than simply teaching the Spanish language and frequently mentioned ways in which they were able to serve as a cultural broker and introduce a new way of thinking or a different worldview to their students. Serving in this role provided teachers a sense of purpose that extended beyond the teaching of the Spanish language alone.

\subsection{1 | Cultural broker for native-English-speaking students}

Participants felt a sense of responsibility in providing their students with exposure to cultures outside of their own (frequently homogeneous or monolingual) cultural setting. Students' limited exposure to other cultures was largely due to a pervasive lack of access to variety in their own personal lived experiences. In addition, participants also felt a sense of camaraderie with other international faculty at their school, helping with the important collegial support aspect of teacher retention.

Luisa taught at the school with the highest percentage of Latinx students from this study, reflective of the growth of the New Latino South. Even so, she was acutely aware of her monolingual English-speaking students' geographic isolation and lack of experiences. For example, she mentioned that through everyday informal conversations, she realized many of her students did not know how to swim, had never seen the ocean, and had never traveled beyond the borders of their rural county. As a result, she and her Latina colleague felt a responsibility as advocates for linguistic and cultural diversity. Luisa frequently showed videos and spoke of her own upbringing in Costa Rica to expose students to other ways of being. She noted, "I feel [Latina teacher colleague] and I are cultural connections, all these kinds of different things, you know."

In contrast, Eduardo worked at a school with one of the lowest percentages of Latinx students, reflective of the continued isolation of many rural areas. Yet even with these differences in student populations, the limited experiences of students remained the same. Eduardo mentioned how close the town was to the mountains and the beach, yet many of his students had never left the town at all. Within the school, he mentioned, "I'm their contact, I'm probably the only Latin American that they've met, other than a few classmates here and there, but the only Latin American adult that they've met." As a result, he, like Luisa, felt a sense of responsibility to serve as a cultural broker for these students and advocated for them to be more open-minded about other cultures and other ethnicities.

As all participants mentioned their students' limited exposure to experiences, it is interesting to note they also mentioned an influx of Visiting International Faculty to staff positions the school struggled to fill. These new teachers were often friendly with the Latinx participants in this study, who took on a mentorship role for many new hires. Natalia reported that her school had recently hired three new teachers from Jamaica. She was hopeful that, no longer the only non-American teacher, students would learn about other cultures outside of her Spanish class alone. The support and collegial camaraderie of the Jamaican teachers were reflected in Natalia's observation, "They think that they know how to dance but I tell them, well, I'm from Colombia, maybe I can! [laughs].”

This sense of responsibility for opening up the worldview of students meant the participants viewed their job as meaningful and important. These teachers challenged dominant ideologies and positioned themselves as agents of change, pushing back against the racism and xenophobia they so frequently experienced. 


\subsection{2 | Cultural broker in the New Latino South}

Though many parts of the rural South continue to be homogeneous with largely Black and White student populations, other parts have seen a dramatic increase in ethnic diversification. Across the board, participants viewed themselves as cultural brokers in a variety of ways. Each of the participants served as a contact person for both Latinx students and their parents who are dominant in Spanish. The schools, unprepared for these students and parents, relied on their Spanish teachers to interpret at meetings, translate forms and letters, and generally support the students as they navigated the emotional and academic adjustments of a new school in a new language.

Guadalupe recounted that she was the only Latinx woman at her school in the late 1980s when she started teaching. Even then, she said, "I had a pretty good rapport with, with all of the kids and the Hispanic kids. I guess knowing that I was Hispanic too, they identified and if they needed other things they could come to my classroom." It is interesting to note that in the 30 years since she began this emotional labor as a cultural broker for Latinx students, there has been little change in how Spanish teachers are positioned and expected to do this work.

To illustrate how schools continue to use their Spanish teachers as cultural brokers, Luisa discussed how mothers of her students wanted to be informed about the academic progress of their children, but the school lacked a Spanish-speaking staff member in the office. She instructed the front office staff to give the mothers her classroom phone number and offered to help at any time. Luisa noted, "They don't even know that there is anybody in the school that actually speaks Spanish, like fluently, both Spanish and English. So, I feel yes, [...] we're right here in the middle helping them and helping the school." As previously mentioned, support from the community is an important aspect of retention in rural areas. The connection these teachers felt with their Latinx students and parents provided a much-needed sense of community they did not always have with the non-Latinx students and parents.

\section{5 | DISCUSSION}

The findings from this study focus on the experiences of Latinx Spanish teachers in the rural South in order to understand the aspects of their job that were difficult and those that were rewarding and meaningful, addressing the first research question. These teachers found ways to serve as advocates for linguistic and cultural diversity in a number of ways in their rural schools and communities, addressing the second research question. By better understanding the lived experiences of these teachers, we can inform the direction of professional efforts to support and retain teachers in similar situations.

\section{1 | Challenges}

The challenges the participants faced were similar to those found in other studies, such as difficulty with motivating students (Azano \& Stewart, 2016) and issues with racism (Beck \& Stevenson, 2016). Reflective of the findings of Acheson et al. (2016), participants in the current study reported experiences of racism tied to immigration. The added dimension of being a Latinx person and a native speaker of Spanish frequently exacerbated these challenges. 
Even though the societal narrative in the United States often revolves around teachers "quitting" or "walking away" from the profession, the reasons for teacher attrition are often complex (Sutcher et al., 2016). One of those reasons is the burnout from the emotional labor of supporting vulnerable students (Acheson et al., 2016). Yet for our participants, emotional labor played out in different ways. Teachers were not only supporting their immigrant students or working with Spanish-speaking families; they were also navigating hostile attitudes from students and parents from the dominant community who appeared not to value the Spanish language or Spanish-speaking people. When the values of the community are reflected in the school, a positive working environment for teachers is more likely (Lowe, 2006). However, for the teachers in the current study, the opposite was reported. Convincing others that the people and cultures from the Spanish-speaking world are worth learning about was a very different sort of emotional labor.

To address this issue, participants reported working hard to maintain a good relationship with stakeholders in both the school and the community. They engaged in activities such as coaching soccer, developing literacy programs, mentoring new teachers, and serving on various committees in order to have contact with other teachers, parents, and school board members. These activities echo recommendations from prior research that suggest teachers engage with the community of their students in meaningful ways in order to support retention. However, this research often focuses on preservice teachers in teacher preparation programs as opposed to encouraging these activities with current teachers (Haddix, 2015; Zeichner, Bowman, Guillen, \& Napolitan, 2016).

When it comes to practicing teachers, professional development is often cited as one possibility to help with retention (Brill \& McCartney, 2008; Kohli, 2019; Mollenkopf, 2009). The specific challenges of the Latinx Spanish teachers in this study revealed a need for professional development that goes beyond best practices in language teaching. Rather, professional development that focuses on intercultural competence and teaching culture in a meaningful way could be helpful in addressing the challenges that come with being the only, or one of the only, Latinx adults in a rural school. With a focus on intercultural competence, Byram, Nichols, and Stevens (2001) stated that the goal is not "to try to change learners' values, but to make them explicit and conscious in any evaluative response to others" (p. 7). Moreover, these authors believed in "a fundamental values position which all language teaching should promote: a position which acknowledges respect for human dignity and equality of human rights as the democratic basis for social interaction [emphasis in the original]" (p. 7). Thus, professional development that better equips teachers to address the racism or xenophobia they see in their communities may be a valuable tool to help with this particular challenge.

\section{2 | Benefits}

The findings revealed not only the challenges but also the benefits of teaching in a rural school in the American South. Teachers felt that they had the freedom to undertake new initiatives, serve in leadership roles, and offer assistance to vulnerable students and families. Both teachers and school administrators in rural areas often wear many hats, resulting in collaboration and opportunities for those who seek them (Starr, 2015).

Because of the access to leadership roles and permission to undertake initiatives of their own choosing, participants viewed this type of trust extended to them as a marker of membership in the school community. The benefit of working in this type of environment is that a 
sense of school and community membership is likely to help support teacher retention (Aldridge \& Fraser, 2016). In short, a supportive school environment is influential in teachers' decisions to stay in the profession.

Our findings revealed that though a sense of professional inclusion was perceived as a benefit to the rural school setting, it was not always an automatic or foregone conclusion. Teachers could be better supported in the future if administrators and colleagues took this responsibility as more than merely a nice thing to do, but rather as an imperative to addressing teacher retention. The burden cannot remain on the shoulders of teachers to seek out opportunities to integrate into the community or adopt leadership roles in the school. Rather, faculty should be intentional about extending these invitations, particularly to teachers of color or international teachers.

\section{3 | Advocates for cultural and linguistic diversity}

The participants in the study served as a point of entry into the Spanish-speaking world in largely monolingual, rural, and isolated communities. The challenges with this work included issues with xenophobia and racism, as well as students' emotional responses ranging from hostility to apathy. However, despite these challenges, the teachers reported feeling a great sense of responsibility and gravity in the work of broadening the worldviews of their students. Introducing their own cultural background as well as other cultures of the Spanish-speaking world was consistently referenced throughout all interviews. Research suggests that a sense of self-efficacy is important in teacher retention (Swanson \& Huff, 2010) and the teachers in this study reported a clear belief in their ability to affect change in their students. Teachers were concerned not only with the linguistic development of Spanish but were also deeply committed to exposing students to other ways of being.

The rural Latinx Spanish teachers in the study recognized the limited perspectives of an insular rural community with little exposure to other worldviews but also recognized the importance of serving as a bridge for the Spanish-speaking people who resided in these rural communities as part of the growing New Latino South. Teachers reported translating and interpreting as needed by their school. Their Spanish language skills were sought by school personnel in a number of ways and in a variety of circumstances. Even as this unofficial and uncompensated work became incorporated as part of their job, they viewed this role not with resentment, but with a sense of responsibility. However, these tasks should be approached with caution. The additional workload can become excessive and burdensome as teachers are not always recognized for taking on these extra duties (Colomer \& Harklau, 2009). Serving as a cultural broker can be both rewarding and exhausting. In order to better support teachers in this work, administrators and colleagues should be vigilant in how much additional labor is expected of their Latinx or Spanish-speaking teachers. Participants in the current study approached this labor with a sense of service and reported being glad to help those in need. Yet prior research cautions that this labor is also much more demanding than many might realize.

\section{6 | LIMITATIONS AND DIRECTIONS FOR FUTURE RESEARCH}

Though findings from this study indicate that Latinx Spanish teachers in the Carolinas experience multiple challenges and forms of support in their rural schools and communities, this 
study does have its limitations. Interviews were conducted with five participants from two states (North Carolina and South Carolina) within the New Latino South. It would be informative to include Latinx teachers from multiple states within the New Latino South, especially states for which no prior studies with Latinx teachers have been conducted. For example, the researchers found no existing studies with Latinx teacher participants in South Carolina during a literature search. More states in the New Latino South must be locations of research (esp. South Carolina) because of the WL teacher shortage. In addition, researchers in other rural areas could contribute to the body of knowledge by investigating the experiences of Latinx teachers nationwide.

Furthermore, three of the five participants in the current study received their teacher training outside the United States in their respective home countries prior to being placed in schools in the Carolinas. Only one participant received training in the same state in which she worked as a teacher. It would be important to know how homegrown teachers of Latino heritage could affect the WL teacher shortage and retention in the New Latino South. The possibility of homegrown teachers may become reality as new communities become established with second and third Latinx generations (Hamann \& Harklau, 2010).

\section{7 | CONCLUSION}

To better understand teacher retention, this study investigated the challenges and support experienced by Latinx teachers in schools and communities in the rural South. Findings showed teachers struggled with the racialization of Spanish and the negative portrayal of immigrants. On the contrary, these teachers felt valued for their roles as cultural brokers advocating linguistic and cultural diversity, as cultural liaisons for Latinx families, and for their language skills that were desired by schools. In particular, the findings showed how navigating the role that these Latinx Spanish teachers fulfilled when advocating for linguistic and cultural diversity went beyond the teaching of the Spanish language.

Shifting the burden of teacher retention requires changing the narrative from focusing on what makes teaching difficult to the point of burnout to one of what makes teaching worthwhile and meaningful. When the conversation about teacher retention continues to reference how teachers "quit" or "abandon" their profession, it is important to consider the issue from the perspective of teachers who love their job. The participants in the current study viewed teaching Spanish as much more than teaching a language. They used their classroom as a way to promote social justice, facilitate a global mindset, confront xenophobia, challenge unexamined beliefs, and offer counter-narratives. Therefore, the burden of teacher retention should not be viewed as solely documenting the reasons why teachers quit. Rather, research in teacher retention should more closely investigate what makes the job worthwhile and meaningful. The teachers in this study clearly demonstrated a passion and enthusiasm for using their classroom to help create a more kind and empathetic reality for students who otherwise wouldn't frequently engage with other ways of thinking. In the WL profession and community, research focusing on how to best support teachers' challenging realities in the rapidly changing New Latino South may provide opportunities for encouragement and validation of the important work these teachers are doing.

\section{ACKNOWLEDGMENTS}

The authors thank ACTFL's Research Priorities Initiative for their financial support in conducting this study. Cornelia Okraski would like to thank her dissertation chair Scott Kissau for 
his ongoing support and Jae Hoon Lim for her expert guidance in the beginning stages of this research.

\section{ORCID}

\section{Stephanie M. Madison (D) http://orcid.org/0000-0002-7757-8658}

\section{REFERENCES}

Acheson, K., Taylor, J., \& Luna, K. (2016). The burnout spiral: The emotion labor of five rural US foreign language teachers. The Modern Language Journal, 100(2), 522-537.

Aldridge, J. M., \& Fraser, B. J. (2016). Teachers' views of their school climate and its relationship with teacher self-efficacy and job satisfaction. Learning Environments Research, 19(2), 291-307.

American Academy of Arts and Sciences (2017). America's languages: Investing in language education for the 21st century. Cambridge, MA: Commission on Language Learning.

Aragon, S. (2016). Teacher shortages: What we know. Teacher Shortage Series. Education Commission of the States. Retrieved from https://files.eric.ed.gov/fulltext/ED565893.pdf

Azano, A., \& Stewart, T. (2016). Confronting challenges at the intersection of rurality, place and teacher preparation: Improving efforts in teacher education to staff rural schools. Global Education Review, 3(1), 108-128.

Beck, S. A., \& Stevenson, A. D. (2016). Shifting racialized identities among Mexican heritage women of the rural south: Brown faces in Black and White places. Hispanic Journal of Behavioral Sciences, 38(1), 31-54.

Boe, E., \& Gilford, D. (1992). Teacher supply, demand, and quality, Washington, DC: National Academy Press.

Bowers, P., Smith, G., Adcox, S., Hawes, J. B., \& Moore, T. (2018, November 14). Minimally adequate: How South Carolina's 'minimally adequate' education system fails too many students. The Post and Courier. Retrieved from https://data.postandcourier.com/saga/minimally-adequate/page/1

Brill, S., \& McCartney, A. (2008). Stopping the revolving door: Increasing teacher retention. Politics \& Policy, 36(5), 750-774.

Bryant, R. (2019). Educational blockade: Structural inequities in segregated southern high schools. Paper presented at the Annual Meeting of the American Education Research Association, Toronto, Canada.

Bunch, B. (2008). Developing a rural definition. Analysis of South Carolina counties (Discussion paper). South Carolina Department of Commerce. Retrieved from https://dc.statelibrary.sc.gov/bitstream/handle/10827/15126/DOC_ Analysis_of_Rural_Definition_2008-1.pdf

Byram, M., Nichols, A. \& Stevens, D. (Eds.). (2001). Developing intercultural competence in practice (Vol. 1) Clevedon, United Kingdom: Multilingual Matters.

Colomer, S. E. (2014). Latina Spanish high school teachers' negotiation of capital in new Latino communities. Bilingual Research Journal, 37(3), 349-365.

Colomer, S., \& Harklau, L. (2009). Spanish teachers as impromptu translators and liaisons in new Latino communities. Foreign Language Annals, 42(4), 658-672.

Cooper, C. R., Denner, J., \& Lopez, E. M. (1999). Cultural brokers: Helping Latino children on pathways toward success. Future of Children, 9(2), 51-57.

Creswell, J. W., \& Plano Clark, V. L. (2018). Designing and conducting mixed methods research (3rd ed.). Thousand Oaks, CA: Sage.

Darling-Hammond, L. (2003). Keeping good teachers: Why it matters, what leaders can do. Educational Leadership, 60(8), 6-13.

Darling-Hammond, L., \& Ducommun, C. E. (2007). Recruiting and retaining teachers: What matters most and what can government do, Washington, DC: The Forum for Education and Democracy.

Flora, C., Flora, J., \& Gasteyer, S. (2016). Rural communities: Legacy and change (5th ed.). Boulder, CO: Westview Press.

Fogle, L. W., \& Moser, K. (2017). Language teacher identities in the Southern United States: Transforming rural schools. Journal of Language, Identity \& Education, 16(2), 65-79.

Haddix, M. (2015). Preparing community-engaged teachers. Theory Into Practice, 54(1), 63-70.

Hamann, E., \& Harklau, L. (2010). Education in the new Latino diaspora. In E. G. Murillo (Ed.), Handbook of Latinos and education: Theory, research, \& practice (pp. 157-169). Mahwah, NJ: Lawrence Erlbaum. 
Hamann, E., Wortham, S., \& Murillo, E. (2002). Education and policy in the new Latino diaspora. In S. Wortham, E. Murillo \& E. Hamann (Eds.), Education in the new Latino diaspora: Policy and politics of identity (pp. 1-16). Westport, CT: Ablex.

Hawes, J., \& Parker, A. (2015, February 7). Schools still separate and unequal. Locals, records detail the path to integration of Charleston's libraries. The Post and Courier. Retrieved from https://www. postandcourier.com/archives/schools-still-separate-and-unequal-locals-records-detail-the-path/article_ 9e4605dd-436b-56c9-b310-30d9e124f2e6.html

Kohli, R. (2019). Lessons for teacher education: The role of critical professional development in teacher of color retention. Journal of Teacher Education, 70(1), 39-50.

Lavalley, M. (2018). Out of the loop: Rural schools are largely left out of research and policy discussions, exacerbating poverty, inequity, and isolation. Center for Public Education. Retrieved from: https://education. wsu.edu/documents/2018/12/center-public-education-rural-schools-report.pdf/

Lowe, J. M. (2006). Rural education: Attracting and retaining teachers in small schools. Rural Educator, 27(2), $28-32$.

Marrow, H. (2011). New destination dreaming: Immigration, race and legal status in the rural American South. Stanford, CA: Stanford University Press.

Merriam, S. B. (1998). Qualitative research and case study applications in education. San Francisco, CA: JosseyBass Publishers.

Mollenkopf, D. L. (2009). Creating highly qualified teachers: Maximizing university resources to provide professional development in rural areas. Rural Educator, 30(3), 34-39.

Monk, D. (2007). Recruiting and retaining high-quality teachers in rural areas. The Future of Children, 17(1), 155-174.

National Association of State Boards of Education. (2016). Educating students in rural America: Capitalizing on strengths, overcoming barriers. Retrieved from http://www.nasbe.org/study-group-report/educating-students-inrural-america-\%09capitalizing-on-strengths-overcoming-barriers/

National Center for Education Statistics. (2018). English language learner (ELL) students enrolled in public elementary and secondary schools, by state: Selected years, fall 2000 through fall 2016. Retrieved from https://nces.ed.gov/ programs/digest/d18/tables/dt18_204.20.asp

Nieto, S. (2017). Becoming sociocultural mediators: What all educators can learn from bilingual and ESL teachers. Issues in Teacher Education, 26(2), 129-141.

North Carolina Rural Center. (n.d.). North Carolina counties. Densities calculated by the Rural Center based on 2014 U.S. Census population estimates. Retrieved from www.ncruralcenter.org

Orellana, M. F. (2009). Translating childhoods: Immigrant youth, language, and culture. New Brunswick, NJ: Rutgers University Press.

Player, D. (2015). The supply and demand for rural teachers. Rural Opportunities Consortium of Idaho. Retrieved from http://www.rociidaho.org/wp-content/uploads/2015/03/ROCI_2015_RuralTeachers_FINAL.pdf

Salas, S. \& Portes, P. R. (Eds.). (2017). US Latinization: Education and the New Latino South. Albany, NY: SUNY Press.

Salinas Jr, C, \& Lozano, A (2019). Mapping and recontextualizing the evolution of the term Latinx: An environmental scanning in higher education. Journal of Latinos and Education, 18(4), 302-315.

Schwartzbeck, T., Redfield, D., Morris, H, \& Hammer, P. (2003). How are rural school districts meeting the teacher quality requirements of No Child Left Behind? Charleston, WV: Appalachian Educational Laboratory. Retrieved from http://aasa.org/uploadedFiles/Policy_and_Advocacy/files/RuralTeacherQualityStudy.pdf

South Carolina Department of Education. (2019). International Visiting Teachers Program. Retrieved from https://ed.sc.gov/educators/recruitment-and-recognition/international-visiting-teachers-program/

Souto-Manning, M. (2006). A Latina teacher's journal: Reflections on language, culture, literacy, and discourse practices. Journal of Latinos and Education, 5(4), 293-304.

Stake, R. E. (1995). The art of case study research, Thousand Oaks, CA: Sage Publications.

Starr, K. (2015). Small rural school leadership: Creating opportunity through collaboration. In S. Clarke \& T. O'Donoghue (Eds.), School leadership in diverse contexts (pp. 43-56). Abingdon, United Kingdom: Routledge.

Sutcher, L., Darling-Hammond, L., \& Carver-Thomas, D. (2016). A coming crisis in teaching? Teacher supply, demand, and shortages in the US. Palo Alto, CA: Learning Policy Institute. 
Swanson, P. (2008). Efficacy and interest profile of foreign language teachers during a time of critical shortage. NECTFL Review, 62, 55-74.

Swanson, P., \& Huff, R. (2010). The relationship of Georgia's rural foreign language teachers' sense of efficacy to teacher attrition. The Rural Educator, 31(3), 16-29.

Swanson, P., \& Mason, S. (2018). The World Language teacher shortage: Taking a new direction. Foreign Language Annals, 51(1), 251-262.

Tippett, R. (2014, July 10). NC in focus: Kindergarten demographics. Carolina Demography. Retrieved from http://demography.cpc.unc.edu/2014/07/10/nc-in-focus-kindergarten-demographics/

United States Census Bureau. (2017). QuickFacts. Retrieved from https://www.census.gov/quickfacts/

U.S. Department of Education. (2017, June). Teacher shortage areas nationwide listing 1990-1991 through 2017-2018. Washington, DC. Retrieved from https://www2.ed.gov/about/offices/list/ope/pol/ateachershortageareasreport201718.pdf

Wainer, A. (2004). The New Latino South and the challenge to public education: Strategies for educators and policymakers in emerging immigrant communities. Tomas Rivera Policy Institute. Retrieved from https:// files.eric.ed.gov/fulltext/ED502060.pdf

Wyatt, T. R., Chapman de Sousa, E. B., \& Mendenhall, S. C. (2017). Professional development as a process of cultural brokering: Positioning coaches as cultural brokers. Journal of Educational Research and Practice, 7(1), 95-110.

Zeichner, K., Bowman, M., Guillen, L., \& Napolitan, K. (2016). Engaging and working in solidarity with local communities in preparing the teachers of their children. Journal of Teacher Education, 67(4), 277-290.

How to cite this article: Okraski CV, Madison SM. Pueblo Pequeño, Infierno Grande: Shifting the burden of Latinx Spanish teacher retention in the rural South. Foreign Language Annals. 2020;1-19. https://doi.org/10.1111/flan.12474

\section{APPENDIX A}

Guiding interview questions:

1. What is your educational and teaching background?

2. Where do you get most of your teaching ideas?

3. Could you describe the context of your upbringing, such as rural or in a city?

4. To what extent do you feel World Languages are valued in your school?

5. What type of exposure to diversity do your students typically experience?

6. If you could change anything about your job to make it better for you and your students, what would it be?

7. How are language and literacy addressed at your school?

8. What is your favorite thing about being a World Language teacher?

9. How does Spanish influence how you are viewed by others?

10. Do you have anything else you would like to share about your experiences as a teacher in this school? 